\title{
PI3 kinase integrates Akt and MAP kinase signaling pathways in the regulation of prostate cancer
}

\author{
ANNA GOC ${ }^{1}$, BELAL AL-HUSEIN $^{1}$, SAMITH T. KOCHUPARAMBIL ${ }^{2}$, JUNXIU LIU $^{1}$ \\ WARREN W.D. HESTON ${ }^{3}$ and PAYANINGAL R. SOMANATH ${ }^{1,4,5}$
}

\author{
${ }^{1}$ Program in Clinical and Experimental Therapeutics, College of Pharmacy, University of Georgia; \\ ${ }^{2}$ Department of Medicine, Medical College of Georgia, Augusta, GA; ${ }^{3}$ Department of Cancer Biology, Cleveland Clinic, \\ Cleveland, OH; ${ }^{4}$ VA Medical Center; ${ }^{5}$ Clinical Pharmacy, Medical College of Georgia, Augusta, GA, USA
}

Received August 3, 2010; Accepted September 29, 2010

DOI: 10.3892/ijo_00000847

\begin{abstract}
PI3 kinase (PI3K), Akt and MAP kinase (MAPK) pathways are central to many classical signaling cascades and are often de-regulated in many cancers. Due to this, inhibitors for a number of key signaling molecules in these pathways such as PI3K, Akt, mTOR, Raf and ERK are currently in clinical trials. In the current study, we investigated the effects of specific inhibition of these signaling molecules, alone or in combinations, on prostate cancer cells. Our study showed that integration of Akt-mTOR and MAPK signaling by PI3K was essential for the EGF-stimulated TRAMP cell migration, proliferation, survival and invasion as well as PC3 and LNCaP C4-2 (C4-2) colony/foci formation. Adenovirus-mediated expression of constitutively active Akt (Ad-myrAkt) in PC3 cells resulted in significant increase in number of foci. Even though PI3K inhibition significantly reduced foci formed by C4-2 cells, none of the Akt, ERK or mTOR inhibitors showed any significant inhibition. This indicated that functional redundancies and/or feed back loops between Akt-mTOR and MAPK signaling exist in prostate cancer. Further studies on cotargeting these signaling molecules revealed that combined inhibition of Akt (or mTOR) and ERK, but not Akt and mTOR, resulted in significant
\end{abstract}

Correspondence to: Dr Payaningal R. Somanath, Program in Clinical and Experimental Therapeutics, College of Pharmacy, University of Georgia, HM1200 Medical College of Georgia, Augusta, GA 30912, USA

E-mail: sshenoy@mail.mcg.edu

Abbreviations: BrDU, 5-bromo-2-deoxyuridine; DMSO, dimethyl sulfoxide; ECM, extracellular matrix; MAPK, mitogen-activated protein kinase; PI3K, PI3 kinase; mTOR, mammalian target of rapamycin; PAGE, polyacrylamide gel electrophoresis; TRAMP, transgenic adenocarcinoma of the mouse prostate; ERK, extracellular regulated kinase; C4-2, LNCaP C4-2; RTK, receptor tyrosine kinase

Key words: PI3 kinase, Akt, mammalian target of rapamycin, mitogen-activated protein kinase, prostate cancer reduction in number of foci formed by the C4-2 cells. Overall, our study demonstrated that the effects of PI3K-mediated prostate cancer growth necessitates a synergism between the Akt and MAPK pathways and suggests cotargeting Akt (or mTOR) and MAPK as an effective method for prostate cancer therapeutic interventions.

\section{Introduction}

Age-related epithelial cancers such as prostate cancer are often caused due to somatic mutations in cell signaling molecules (1). The occurrence of androgen-insensitive prostate cancers, often due to the resistance developed by activating mutations in many signaling molecules, makes it even more difficult to treat these cancers using conventional androgen therapy (2). Research has for a long time been focused on targeting growth factors (e.g. Bevacizumab), receptor tyrosine kinases (RTKs) (e.g. Sorafenib) and integrins (e.g. Cilengitide) (3) for treating many cancers. Many of these trials demonstrated development of tumor resistance to therapy (4). Hence, attention has recently shifted to use of intra-cellular signaling molecules to target for cancer therapy.

Mutations in oncogenes such as Ras (5), Src (6), Raf (7) and myc (8). have been linked to oncogenic transformation, tumor progression and metastasis. De-regulation of one or more of these signaling pathways is always associated with tumor growth and metastasis (1). The loss of the tumor suppressor gene encoding phosphatase and tensin homolog deleted on chromosome 10 (PTEN) is common in prostate cancer $(9,10)$. Loss of PTEN activity, in turn, results in the activation of many signaling pathways that are deregulated during prostate cancer that include classical PI3 kinase (PI3K)-Akt $(10,11)$ and MAP kinase (MAPK) cascades (12). Because of this significance, there is considerable interest in the importance of downstream signaling components of PTEN, mainly the PI3K/Akt/mTOR and MAPK pathways in developing therapeutics for prostate cancer.

PTEN functions as a lipid phosphatase that is responsible for the dephosphorylation of phosphatidylinositol triphosphate (PIP3), a second messenger of PI3K at the plasma membrane $(13,14)$. In the absence of PTEN activity, intracellular PIP3 levels will be elevated due to the conversion of 
phosphatidylinositol bisphosphate (PIP2) to PIP3 by activated PI3K $(13,14)$. This, in turn, binds to the PH-domain of PDK1 and Akt and recruits them to the plasma membrane (15), where PDK1 phosphorylates Akt on Thr308 in the activation loop of the kinase domain. Many kinases have been proposed to phosphorylate Ser473 of Akt, which is necessary for its complete activation. Some of them include integrin-linked kinase (ILK) (16), mTORC2 (17) and Akt itself (18). Although mTORC2 is a Rapamycin-insensitive complex, long-term treatment can inhibit its activity and inhibit Akt Ser473 phosphorylation (17).

Human prostate cancer cell lines such as PC3 and LNCaP C4-2 (C4-2) has been shown to contain higher levels of activated Akt $(19,20)$. Akt has been shown to suppress androgen-induced apoptosis via phosphorylation and inhibition of androgen receptor (21). Conditional activation of Akt has been shown to promote androgen-independent progression and was found essential to neuroendocrine differentiation of prostate cancer (22). Development of hormone insensitivity in patients who have been on long-term androgen ablation therapy for prostate cancer is associated with the reinforcement of the PI3K-Akt pathway (23). Loss of PTEN (24) as well as elevated levels of PI3K activity (25), and phosphorylated Akt (Serine 473; active) (23) have been shown to correlate with higher Gleason score and are excellent predictors of poor clinical outcome in prostate cancer patients.

MAPK pathway that includes signaling molecules such as Raf and ERK is another mediator of prostate cancer progression (26). Inhibition of PI3K has been shown to inhibit phosphorylation of ERK in Rat1 cells (27). In this previous study using a Rat1 cell model, we showed that expression of myrAkt (constitutively active) resulted in oncogenic transformation (27). Although expression of Rat1 cells with cRaf, an upstream activator of ERK, did not induce oncogenic transformation, co-expression of cRaf along with constitutively active Akt resulted in enhanced rate of oncogenic transformation, compared to cells expressing myrAkt alone (27). This suggests that cooperation between PI3K-Akt and cRaf-ERK signaling exists in many cancers. In the current study, we have attempted to answer the question whether integration of Akt-mTOR and MAPK pathways by PTENPI3K is necessary for prostate cancer. Our study reveals that targeting Akt (or mTOR) and ERK concomitantly can be a suitable strategy for prostate cancer therapy.

\section{Material and methods}

Cell lines, reagents, and antibodies. Mouse TRAMP cell lines: 1) non-tumorigenic, non-metastatic (TR-C2A, TR-C2D, TR-C3); 2) tumorigenic, non-metastatic (TR-C1, TR-C2, TR$\mathrm{C} 2 \mathrm{G}$ ); and 3) tumorigenic, metastatic (TR-C2N, TR-C2H) (28) were a kind gift from Dr Barabara Foster, Baylor College of Medicine, TX to Dr Warren Heston. Human PC3 and C4-2 cell lines were obtained from ATCC (Manassas, VA). All cell lines were maintained in DMEM (HyClone) with $10 \%$ fetal bovine serum, $100 \mathrm{U} / \mathrm{ml}$ penicillin, and $100 \mu \mathrm{g} / \mathrm{ml}$ streptomycin in a $5 \% \mathrm{CO}_{2}$ atmosphere at $37^{\circ} \mathrm{C}$. EGF $(50 \mu \mathrm{M})$ (R\&D Biosystems) was prepared in DMSO. Inhibitors of PI3K (LY294002), Akt (SH-5), mTOR (Rapamycin) and MEK (U0126) (EMD Biosciences) were dissolved in DMSO to make a stock solution containing: $10 \mathrm{mM}$ of LY294002, $10 \mathrm{mM}$ of SH-5, $25 \mathrm{nM}$ of Rapamycin and $10 \mathrm{mM}$ of U0126. Primary antibodies such as: anti-Akt, anti-phospho-Akt ${ }^{\mathrm{S473}}$, anti-phospho-S6-kinase ${ }^{\mathrm{T} 389}$, anti-phospho-ribosomal S6 protein $^{\mathrm{S} 235 / 236}$, anti-cRaf ${ }^{\mathrm{S} 259}$ and anti-phospho-4EBP1 ${ }^{\mathrm{T} 37 / 46}$ were purchased from Cell Signaling (Boston, MA). Primary antibodies against $B$-actin were purchased from Sigma (St. Louis, MO). All secondary antibodies were obtained from BioRad.

Migration assay. Actively growing TRAMP cell lines (TRC2D, TR-C2 and TR-C2N) were used for migration assays in the presence of EGF as well as inhibitors of: PI3K (LY294002), Akt (SH-5), mTOR (Rapamycin) and MEK (U0126). Control cells were treated with either 0.1\% DMSO (vehicle control) or only $50 \mu \mathrm{M}$ EGF. Cells were grown in 12-well plates to reach confluence and then serum starved for $3 \mathrm{~h}$. A scratch was made in the monolayer following treatments as follows: $50 \mu \mathrm{M}$ EGF, $50 \mu \mathrm{M}$ EGF $+10 \mu \mathrm{M}$ $\mathrm{LY} 294002,50 \mu \mathrm{M} \mathrm{EGF}+10 \mu \mathrm{M} \mathrm{SH}-5,50 \mu \mathrm{M} \mathrm{EGF}+25 \mathrm{nM}$ Rapamycin, $50 \mu \mathrm{M} \mathrm{EGF}+10 \mu \mathrm{M}$ U0126 or DMSO (control) for $16 \mathrm{~h}$. After $16 \mathrm{~h}$, pictures were taken again. The rate of migration (as measured by scratch recovery) was calculated using the following equation $\left(1-\mathrm{T}_{16} / \mathrm{T}_{0}\right) \times 100$. The data are presented as mean $\pm \operatorname{SD}(n=3)$.

Invasion assay. The invasion of mouse TRAMP cell lines was measured using BD BioCoat Tumor Invasion Kit (BD Biosciences) coated with BD Matrigel Matrix according to the manufacturer's protocol. Briefly, TRAMP cell lines: TRC2D, TR-C2 and TR-C2N cells were labeled with BD DilC 12 fluorescence dye and seeded onto the upper chamber of 96-well Transwell plate at a density of $1 \times 10^{4}$ cells per well in $400 \mu \mathrm{l}$ medium. DMEM medium containing $10 \%$ FBS was then added to the lower chamber. After $24 \mathrm{~h}$, the cells were incubated in serum-free medium supplemented with $50 \mu \mathrm{M}$ EGF plus $10 \mu \mathrm{M} \mathrm{LY} 294002,10 \mu \mathrm{M} \mathrm{SH}-5,25 \mathrm{nM}$ Rapamycin, or $10 \mu \mathrm{M}$ U0126 for $16 \mathrm{~h}$. Control cells were treated with $0.1 \%$ DMSO (vehicle control) or only $50 \mu \mathrm{M}$ EGF. The absorbance of the stained cells was measured after 12 and 24 $\mathrm{h}$ on an ELISA plate reader. The data are presented as mean $\pm \mathrm{SD}(\mathrm{n}=3)$.

Cell doubling time assay. In each experiment, cell doubling time was determined according to direct cell count considering the logarithmic growth of cancer cells (www.doublingtime.com). For direct cell count approximately 20 cells per well were seeded in $400 \mu 1$ medium on 48 -well plate, in quadruplicates. After $24 \mathrm{~h}$ medium was replaced on DMEM without serum, cells were counted and inhibitors in the presence and absence of EGF were added as follows: $50 \mu \mathrm{M}$ EGF, $50 \mu \mathrm{M}$ EGF $+10 \mu \mathrm{M}$ LY294002, $50 \mu \mathrm{M}$ EGF $+10 \mu \mathrm{M}$ $\mathrm{SH}-5,50 \mu \mathrm{M}$ EGF + $25 \mathrm{nM}$ Rapamycin, $50 \mu \mathrm{M}$ EGF $+10 \mu \mathrm{M}$ U0126 or $0.1 \%$ DMSO (control) for $16 \mathrm{~h}$. After $16 \mathrm{~h}$, cells were counted again. The cell doubling time was calculated as the mean $\pm \operatorname{SD}(n=6)$.

Apoptosis assay. Cytoplasmic histone-associated DNA fragments were quantified by using the Cell Death Detection ELISA $^{\text {PLUS }}$ Kit (Roche Applied Science, Indianapolis, IN) 
according to the manufacturer's protocol. Briefly, TRAMP cell lines: TR-C2D, TR-C2 and TR-C2N cells were seeded in 96-well plates at a density of $1 \times 10^{4}$ cells/well. After $24 \mathrm{~h}$, the cells were incubated in serum-free medium supplemented with $50 \mu \mathrm{M}$ EGF alone or along with $10 \mu \mathrm{M}$ of LY294002, $10 \mu \mathrm{M}$ of SH-5, $25 \mathrm{nM}$ of Rapamycin and $10 \mu \mathrm{M}$ of $\mathrm{U} 0126$ for $16 \mathrm{~h}$. Control cells were treated with $0.1 \%$ DMSO (vehicle control) or $50 \mu \mathrm{M}$ EGF alone. Cells were lysed, centrifuged $(200 \mathrm{x} \mathrm{g}$ for $10 \mathrm{~min})$ and the collected supernatant was subjected to ELISA. The absorbance was measured at $405 \mathrm{~nm}$ (reference wavelength at $492 \mathrm{~nm}$ ). The data are presented as mean \pm SD $(n=3)$. Cell death was calculated based on trypan blue staining and a ratio between live cells vs. total cells was determined.

Cell proliferation assay. The effect of inhibitors on proliferation of TRAMP cell lines was determined using the nonradioactive BrDU-based cell proliferation assay (Roche, Basel, Switzerland) according to the manufacturer's protocol. Briefly, mouse TRAMP cell lines: TR-C2D, TR-C2 and TR$\mathrm{C} 2 \mathrm{~N}$ cells were seeded in 96-well plates at a density of $5 \times 10^{3}$ cells per well. After $24 \mathrm{~h}$, the cells were incubated in serumfree medium supplemented with $50 \mu \mathrm{M}$ EGF plus $10 \mu \mathrm{M}$ of LY294002, $10 \mu \mathrm{M}$ of SH-5, $25 \mathrm{nM}$ of Rapamycin and $10 \mu \mathrm{M}$ of U0126 for $16 \mathrm{~h}$. Control cells were treated with $0.1 \%$ DMSO (vehicle control) or only $50 \mu \mathrm{M}$ EGF. After treatment, the cells were subject to a 5-bromo-2-deoxyuridine assay using the BrDU Labeling and Detection Kit III (Roche Applied Science), according to the manufacturer's protocol. BrDU incorporation into the DNA was determined by measuring the absorbance at both 450 and $690 \mathrm{~nm}$ on an ELISA plate reader. The data are presented as mean $\pm \mathrm{SD}$ $(n=3)$.

Colony formation assay. Colony formation assay was performed using standard protocol $(29,30)$. In this approach, PC3 or C4-2 cells were cultured on 6-well plates till monolayer was reached. The wells were treated with respective inhibitors, alone or in combinations, in the presence of serum and were incubated further for another 5 days. Inhibitors of PI3K, Akt, mTOR and MAPK, which are $10 \mu \mathrm{M} \mathrm{LY294002,}$ $10 \mu \mathrm{M}$ SH-5, $25 \mathrm{nM}$ Rapamycin and $10 \mu \mathrm{M}$ U0126, respectively were used alone or in following combinations $(10 \mu \mathrm{M} \mathrm{SH}-5+25 \mathrm{nM}$ Rapamycin, $10 \mu \mathrm{M}$ SH-5 + $10 \mu \mathrm{M}$ U0126, $10 \mu \mathrm{M}$ U0126 + $25 \mathrm{nM}$ Rapamycin). At 5 days post treatment, each of the wells was counted for the number of colonies and were compared to control. Plates were fixed using crystal violet and counted visually or using Image $\mathbf{J}$ software. The data are presented as mean $\pm \operatorname{SD}(n=3)$.

Western analysis. TRAMP cell lines were cultured to reach monolayer in serum containing medium (TR-C1A, TR-C2D, TR-C1, TR-C2, TR-C2H and TR-C2N) or serum starved for $5 \mathrm{~h}(\mathrm{TR}-\mathrm{C} 2 \mathrm{D}, \mathrm{TR}-\mathrm{C} 2$ and TR-C2N) and treated with $50 \mu \mathrm{M}$ $\mathrm{EGF}, 50 \mu \mathrm{M}$ EGF $+10 \mu \mathrm{M}$ LY294002, $50 \mu \mathrm{M}$ EGF $+10 \mu \mathrm{M}$ $\mathrm{SH}-5,50 \mu \mathrm{M} \mathrm{EGF}+25 \mathrm{nM}$ Rapamycin, and $50 \mu \mathrm{M} \mathrm{EGF}+$ $10 \mu \mathrm{M} \mathrm{U} 0126$ for $16 \mathrm{~h}$ and $30 \mathrm{~min}$. Control cells were treated with $0.1 \%$ DMSO (vehicle control). Whole cell lysates were prepared using lysis buffer [50 mM Tris- $\mathrm{HCl}(\mathrm{pH} 7.4), 1 \%$ Triton X-100, $150 \mathrm{mM} \mathrm{NaCl}, 1 \mathrm{mM}$ EDTA, $2 \mathrm{mM} \mathrm{Na}_{3} \mathrm{VO}_{4}$,

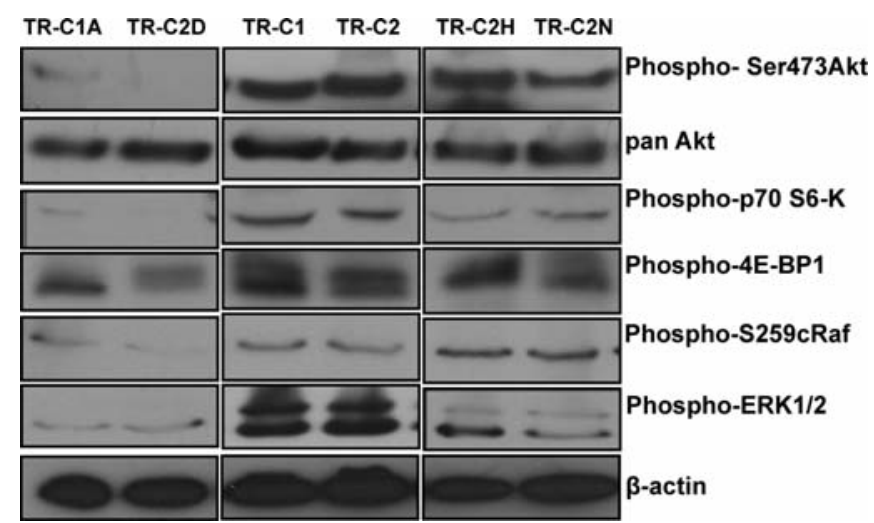

Figure 1. Correlation between activation of PI3K-Akt as well as MAPK pathways and tumorigenic potential in prostate cancer cells. Three sets of TRAMP cell lines namely 1) non-tumorigenic, non-metastatic (TR-C1A, TR-C2D, TR-C3); 2) tumorigenic, non-metastatic (TR-C1, TR-C2, TR-C2G); as well as 3) tumorigenic and metastatic (TR-C2H, TR-C2N) cell lines were subjected for Western blot analyses to determine a correlation between their tumorigenic and metastatic potential as well as phosphorylation and expression pattern of key signaling molecules under the control of PI3K-Akt-MAPK signaling loop. Cell lysates were subjected for Western analyses using $\mathrm{pAkt}^{\mathrm{S} 473}$, pS6-Kinase ${ }^{\mathrm{T} 389}, \mathrm{p} 4 \mathrm{EBP} 1^{\mathrm{T} 37 / 46}$, pRibosomal S6 protein ${ }^{\mathrm{S} 236 / 237}$, $\mathrm{pcRaf}^{259}$ and $\mathrm{p}^{42 / 44} \mathrm{ERK} 1 / 2$.

and 1X Complete protease inhibitors (Roche Applied Science)]. The protein concentration was measured by the Dc protein assay (Bio-Rad). Western analyses were performed using standard Laemmli's method as done previously (31).

Statistical analysis. Mean activities were calculated from three independent experiments done at least in triplicates. The Student's two-tailed t-test was used to determine significant differences between treatment and control values.

\section{Results}

Tumorigenic and metastatic potential of prostate cancer cells correlate with the activity levels of PI3K-Akt and MAPK pathways. In order to do a comparison between the activity status of PI3K-Akt as well as MAPK pathways and the tumorigenic and metastatic potential of prostate cancer cells, we employed 6 mouse TRAMP prostate cell lines, which are categorized into i) non-tumorigenic (TR-C1A, TR-C2D), ii) tumorigenic (TR-C1, TR-C2) as well as iii) tumorigenic and highly metastatic (TR-C2H, TR-C2N) and subjected them to Western blot analysis of signaling molecules involved in the PI3K and MAPK pathways in comparable conditions. Our results indicated that, levels of phosphorylated Akt, cRaf, ERK1/2 and substrates on mTOR such as P70 S6 kinase and 4E-BP1 were higher in tumorigenic (TR-C1, TR-C2) and metastatic (TR-C2H, TR-C2N) cells compared to nontumorigenic (TR-C1A, TR-C2D) TRAMP cell lines (Fig. 1). We next determined the effects of inhibitions of PI3K, Akt, mTOR and MAPK on representative cell lines from each of the non-tumorigenic (TR-C2D), tumorigenic (TR-C2) and metastatic (TR-C2N) groups using inhibitors, LY294002, SH-5, Rapamycin and U0126, respectively. While treatment with EGF resulted in enhanced phosphorylations of Akt, ERK and mTOR substrates, a decrease in the levels of 


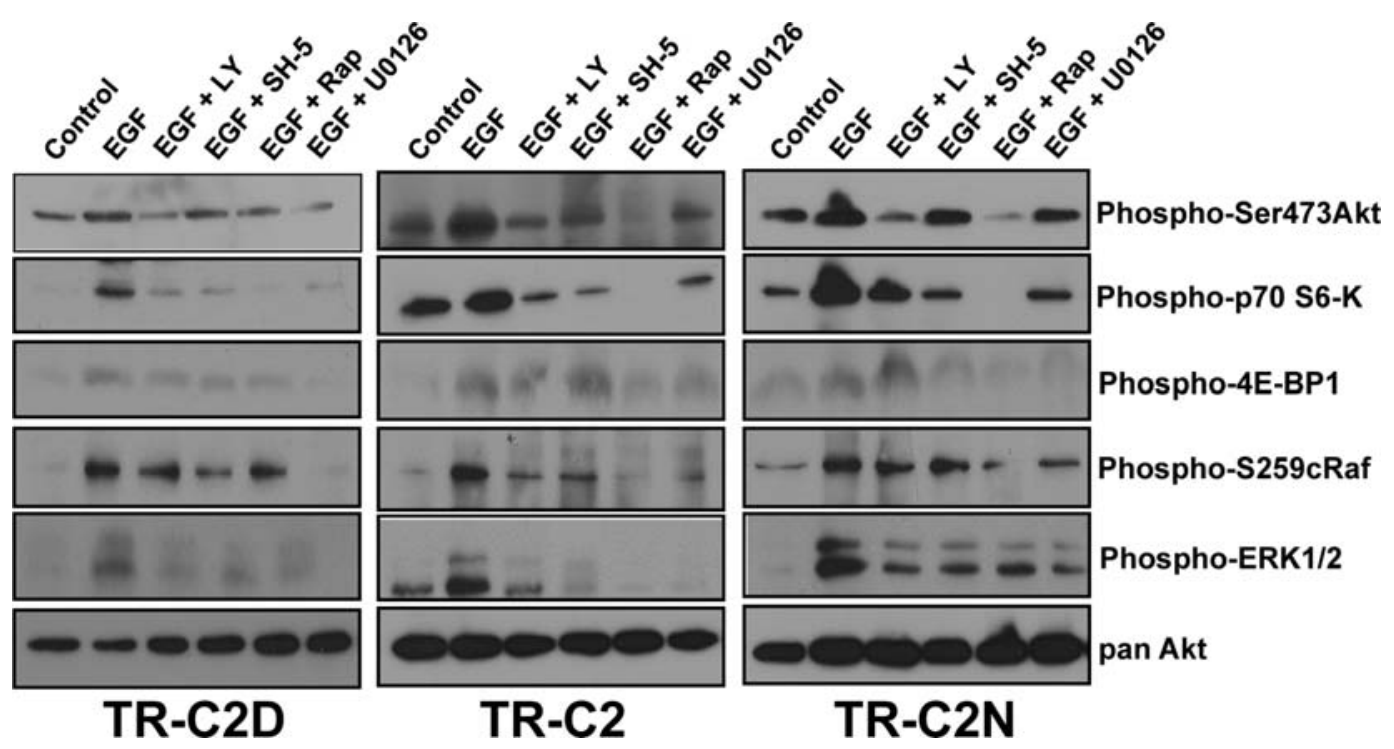

Figure 2. Effect of PI3K, Akt, mTOR and MAPK inhibitors on EGF-induced phosphorylations of downstream signaling molecules in TRAMP cells. Three sets of TRAMP cell lines namely 1) non-tumorigenic, non-metastatic (TR-C1A, TR-C2D, TR-C3); 2) tumorigenic, non-metastatic (TR-C1, TR-C2, TR-C2G); as well as 3) tumorigenic and metastatic (TR-C2H, TR-C2N) cell lines were subjected for Western blot analyses after incubated for 30 min with 50 pM EGF in the presence or absence of inhibitors of PI3K (LY294002), Akt (SH-5), mTOR (Rapamycin) and MEK (U0126). The cell lysates were subjected for

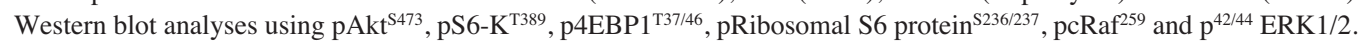

A

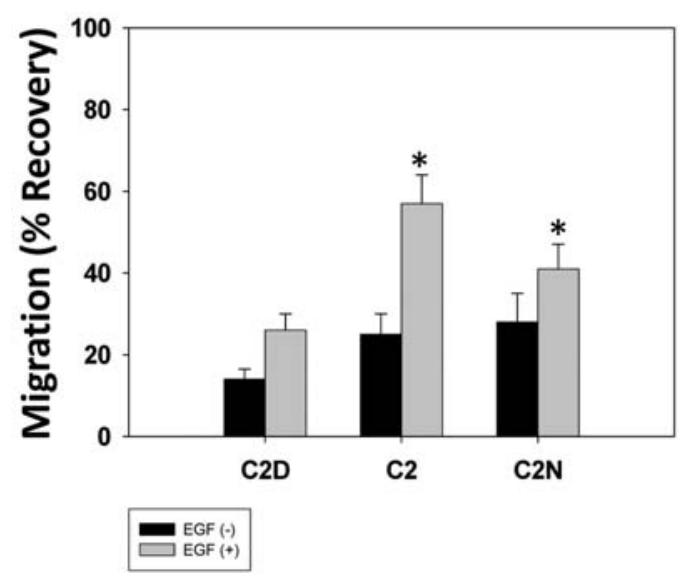

B

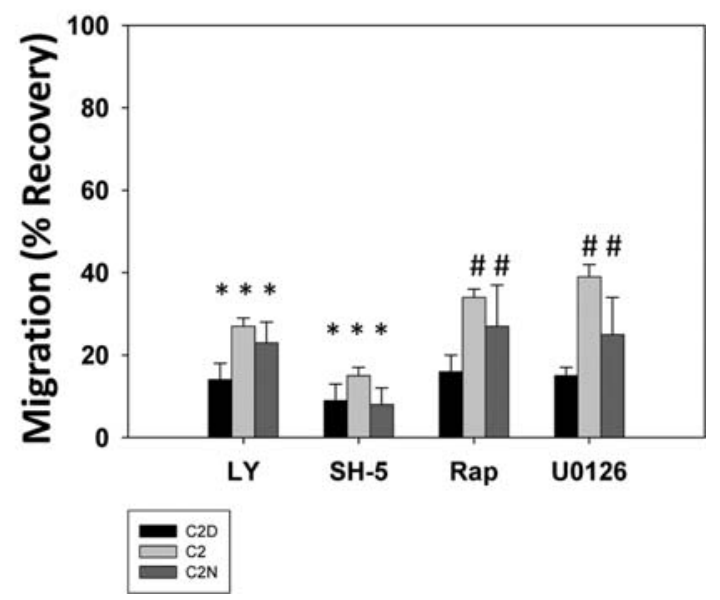

Figure 3. Akt is the predominant regulator of TRAMP cell migration downstream of PI3K activation. Actively growing, selected TRAMP cell lines from each group (TR-C2D, TR-C2 and TR-C2N) were used for migration assays in the presence and absence of EGF (panel A) as well as PI3K, Akt, mTOR and MEK inhibitors (panel B). Cells were grown to reach confluence and then serum starved. A scratch was made in the monolayer following treatments as follows: DMSO (control), EGF, EGF + PI3K inhibitor (LY294002), EGF + Akt inhibitor (SH-5), EGF + mTOR inhibitor (Rapamycin), EGF + MAPK inhibitor (U0126) for $16 \mathrm{~h}$. The data are presented as mean $\pm \mathrm{SD}(\mathrm{n}=3) ;{ }^{*} \mathrm{p}<0.001,{ }^{\#} \mathrm{p}<0.05$.

phosphorylated Akt and ERK was seen in all three TRAMP cell lines with PI3K inhibition by LY294002 (Fig. 2), indicating that PI3K is responsible for the activation of both Akt and ERK. As expected, inhibition of MEK (U0126) and Akt (SH-5) resulted in decreased phosphorylations of ERK and mTOR substrates (P70 S6 kinase and 4E-BP1). Interestingly, while Akt inhibition resulted in decreased ERK phosphorylation, inhibition of MAPK resulted in partial reduction in phosphorylated Akt levels (Fig. 2). Also, specific inhibition of mTOR by Rapamycin treatment reduced phosphorylation of both Akt and ERK. Together these results indicate that cross-talk between signaling molecules exists in prostate cancer cells in the regulation of tumor growth and metastasis.

Inhibitors of PI3K, Akt, mTOR and MAPK significantly inhibit prostate cancer cell migration. A role for Akt and MAPK pathways has been reported in the migration of a number of cancer cell types $(32,33)$. To determine if Akt/ $\mathrm{mTOR}$ and/or MAPK is involved in prostate cancer cell migration with respect to its tumorigenic and metastatic potential, we incubated TR-C2D, TR-C2 and TR-C2N cell lines with inhibitors of PI3K (LY294002), Akt (SH-5), 

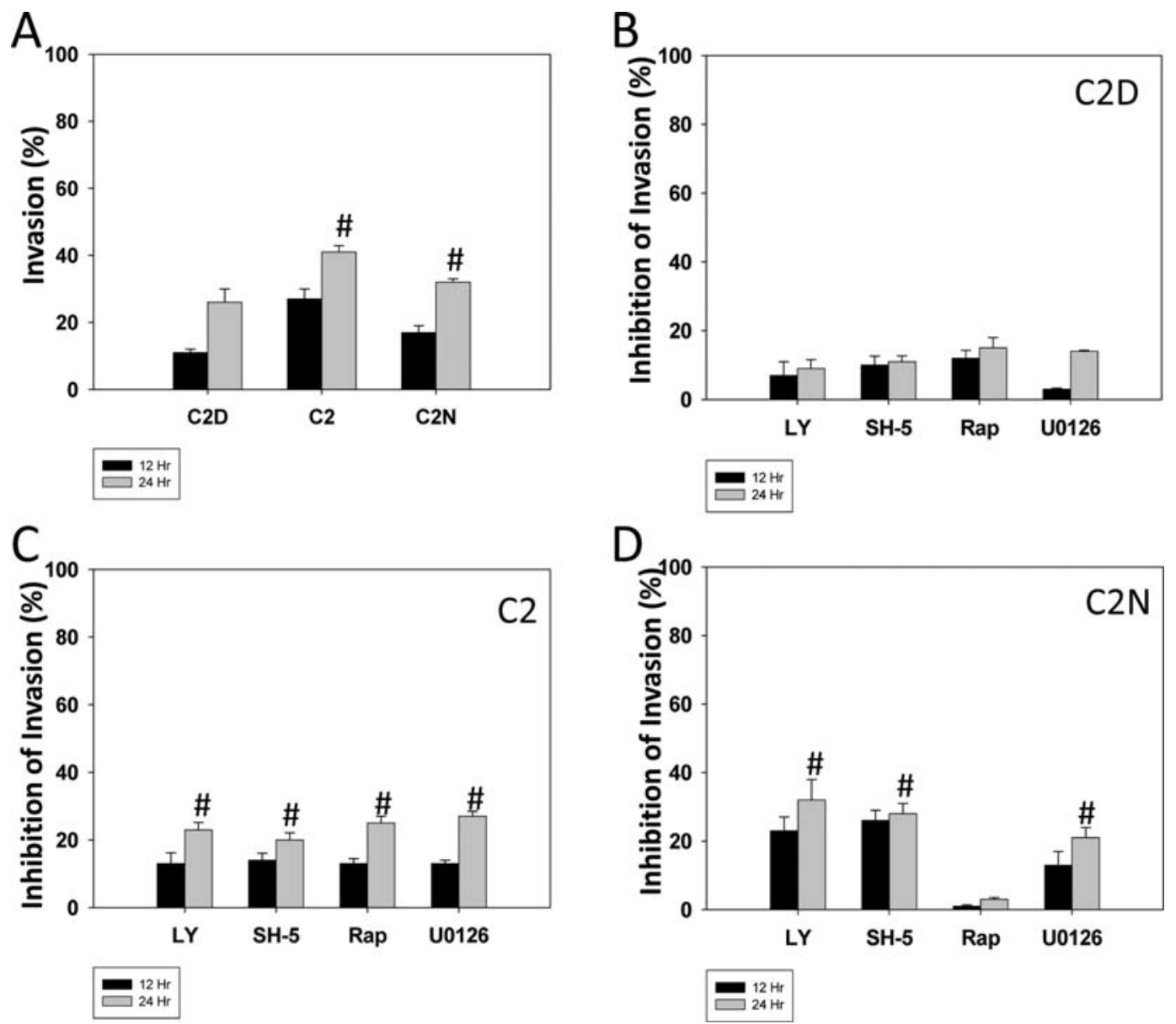

Figure 4. Akt and MAPK cooperate in regulating TRAMP cell invasion downstream of PI3K activation. Actively growing TRAMP cell lines (TR-C1D, TR$\mathrm{C} 2$ and TR-C2N) were stained in situ with BD DilC 12 in concentration $5 \mu \mathrm{g} / \mathrm{ml}$ for $60 \mathrm{~min}$ and plated in 96-well plates at a density of $1 \times 10^{4}$ cells/well in triplicates. After $24 \mathrm{~h}$ incubation in a $\mathrm{CO}_{2}$ incubator at $37^{\circ} \mathrm{C}$, cells were treated with $0.05 \%$ DMSO (vehicle) or $50 \mu \mathrm{M} \mathrm{EGF}$ (panel A) as well as EGF plus the indicated concentrations of PI3K, Akt, mTOR and MAPK inhibitors (LY294002, SH-5, Rapamycin and U0126, respectively) and further incubated for $24 \mathrm{~h}$ (panels B, C and D). Cell invasion was measured at 12 and $24 \mathrm{~h}$. The data are presented as mean $\pm S D(n=3) ; " p p<0.05$.

mTOR (Rapamycin) and MEK (U0126) in the presence or absence of EGF $(50 \mathrm{ng} / \mathrm{ml})$ and subjected them to a migration assay using a monolayer scratch healing method as performed previously (31). When compared to the control, tumorigenic and metastatic cell lines exhibited significantly higher rate of migration $(\mathrm{p}<0.001)$ (Fig. 3A). While incubation with EGF significantly enhanced cell migration in all the TRAMP cell lines, co-incubation of TRAMP cell lines with EGF and one of the inhibitors of PI3K (LY294002; p<0.001), Akt (SH-5; $\mathrm{p}<0.001)$, mTOR (Rapamycin; $\mathrm{p}<0.05$ ) or MEK $(\mathrm{U} 0126 ; \mathrm{p}<0.05)$ resulted in significant reduction in EGFmediated cell migration (Fig. 3B), suggesting that PI3K/ Akt/mTOR and the Ras/Raf/MEK/ERK pathways play a significant role in the directional migration of prostate cancer cells. Our observation is that the effects of PI3K and Akt inhibition on TRAMP cell migrations are much more robust compared to specific inhibition of mTOR or MEK/ERK.

Inhibitors of PI3K, Akt, mTOR and MAPK significantly inhibit prostate cancer cell invasion. We next evaluated the effects of PI3K, Akt, mTOR and MAPK inhibition on prostate cancer cell invasion. To do this, we incubated TRC2D, TR-C2 and TR-C2N cell lines with inhibitors of PI3K
(LY294002), Akt (SH-5), mTOR (Rapamycin) and MEK (U0126) in the presence and absence of EGF and subjected them for an invasion assay. Invasiveness of TRAMP cell lines were measured at 12 and $24 \mathrm{~h}$ after the cells were plated on Matrigel-coated filters in the presence and absence of EGF and inhibitors. As expected, our results indicated that TR-C2D (non-tumorigenic) cells were not invasive (Fig. 4A and $\mathrm{B}$ ) and rate of invasion by TR-C2 (tumorigenic) and TR$\mathrm{C} 2 \mathrm{~N}$ (metastatic) cells were significantly higher compared to TR-C2D in response to EGF. Inhibition of PI3K, Akt, mTOR and MAPK resulted in significant inhibition in the rate of invasion by TR-C2 cells (Fig. 4C) $(\mathrm{p}<0.05)$. Similar results were obtained from the TR-C2N cell line, except that Rapamycin did not have a significant inhibitory effect on invasiveness (Fig. 4D).

Akt, but not mTOR or MAPK is necessary for prostate cancer cell survival. Next, we determined the effects of PI3K, Akt, mTOR and MEK inhibitors on prostate cancer cell survival and apoptosis. First, we performed a trypan blue assay to determine if there is a difference in cell survival between TR$\mathrm{C} 2 \mathrm{D}, \mathrm{TR}-\mathrm{C} 2$ and TR-C2N cell lines at the basal levels. Our data indicate that there are no differences in the rate of cell 
A

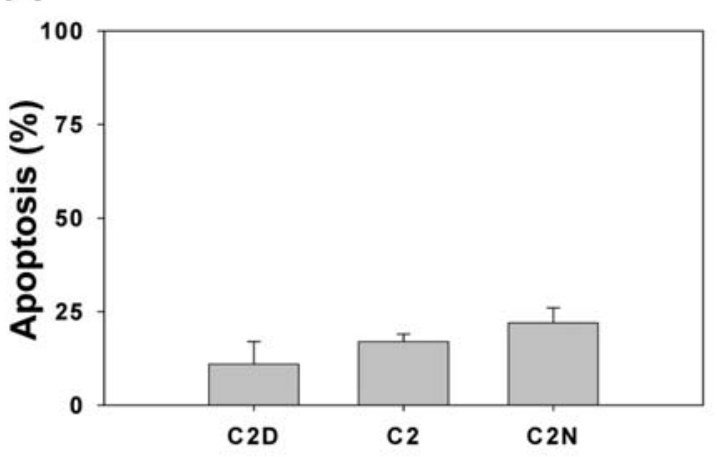

C

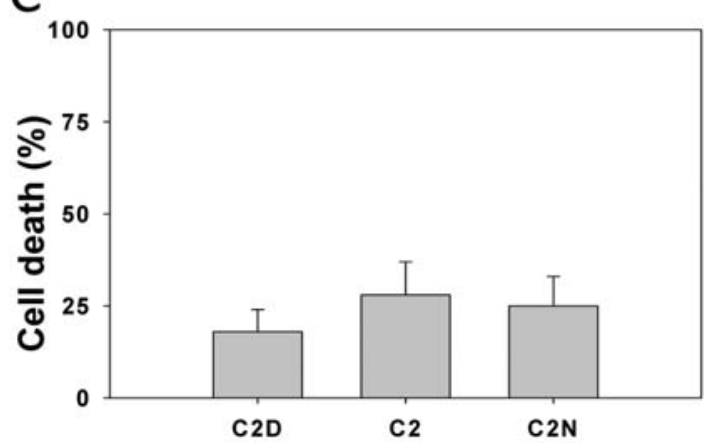

B

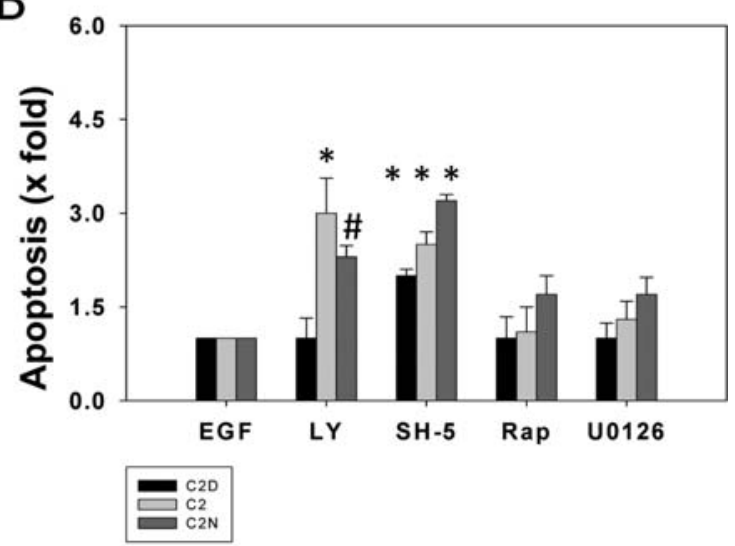

D

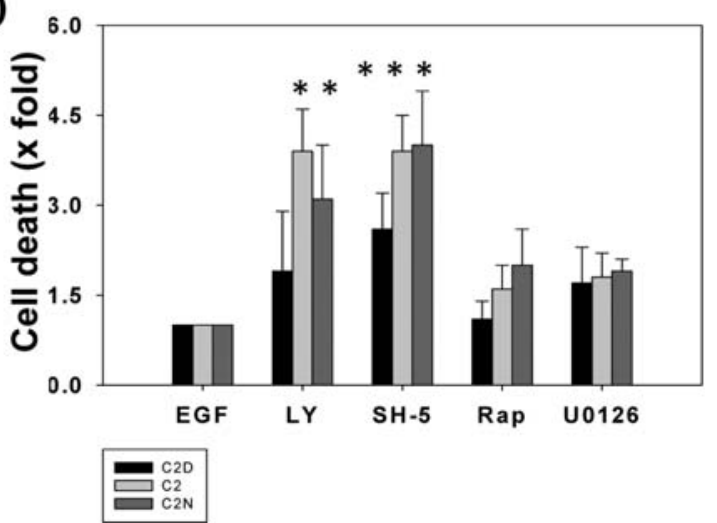

Figure 5. Akt, but not mTOR and MAPK is necessary for PI3K-mediated prostate cancer cell survival. Actively growing TRAMP cell lines (TR-C1D, TR-C2 and TR-C2N) were plated in 96-well plates at a density of $5 \times 10^{3}$ cells/well in triplicates. After $24 \mathrm{~h}$ incubation in a $\mathrm{CO}_{2}$ incubator at $37^{\circ} \mathrm{C}$, cells were treated with $0.05 \%$ DMSO (vehicle) or $50 \mu \mathrm{M}$ EGF (panels A and C) as well as EGF plus the indicated concentrations of PI3K, Akt, mTOR and c-Raf inhibitors (LY294002, SH-5, Rapamycin and U0126, respectively) and further incubated for $16 \mathrm{~h}$ (panel B). Cell apoptosis was determined by the cytoplasmic histoneassociated-DNA-fragments assay (Roche). Cell death (viability test) was performed by Trypan blue exclusion method. The data are presented as mean \pm SD $(\mathrm{n}=3) ;{ }^{*} \mathrm{p}<0.001,{ }^{*} \mathrm{p}<0.05$.

death (viability) or apoptosis between the cell lines. However, there was a trend for increased cell death in metastatic (TR-C2N) compared to non-tumorigenic (TRC2D) cells. Following treatments with PI3K, Akt, mTOR and MAPK inhibitors (0.05\% DMSO was used in control) and/or EGF, we observed that EGF dependent cell survival was significantly reduced by PI3K and Akt inhibitors, but not by mTOR and MAPK inhibitors (Fig. 5A and B). Similarly, treatment with PI3K and Akt inhibitors significantly enhanced apoptosis in all the 3 TRAMP cell lines $(p<0.001$ for LY294002 and SH-5 for TR-C2) and (p<0.001 for SH-5; $\mathrm{p}<0.05$ for LY294002 for TR-C2N). However, treatment with $\mathrm{mTOR}$ and MAPK inhibitors did not show a significant effect on apoptosis (Fig. 5C and D). Taken together, our results show the importance of PI3K-Akt signaling in cell survival.

PI3K, Akt, mTOR and ERK are necessary for the proliferation of prostate cancer cells. Based on the positive correlation that was observed between biochemical and functional response of EGF and inhibitors PI3K and MAPK pathways on TR-C2D, TR-C2 and TR-C2N mouse cell lines, we examined the effects of these inhibitors on EGF-stimulated prostate cancer cell proliferation. Ability of prostate cells to proliferate was tested by two different methods; 1) direct counting of differences in number of viable cells on a 0 and 24-h period time to determine the doubling time and 2) using a non-radioactive, BrDU incorporation assay. In the presence of EGF, we observed enhanced proliferation in all the TRAMP cell lines used in the assay. There was a significant decrease in doubling time and increase in proliferation in TR-C2 (Fig. 6A and $\mathrm{C}, \mathrm{p}<0.001$ ) and TR-C2N (Fig. 5A, $\mathrm{p}<0.001$; Fig. $6 \mathrm{C}, \mathrm{p}<0.05)$ compared to TR-C2D cells indicating that TR-C2 and TR-C2N cell lines, which have higher PI3K and MAPK activities proliferate faster than the TR-C2D, which have relatively reduced activities of PI3K and MAPK. In contrast, treatment of all three cell lines with all inhibitors of PI3K, Akt, mTOR and MEK for $16 \mathrm{~h}$ resulted in reduced proliferation (Fig. $6 \mathrm{~B}$ and $\mathrm{D}, \mathrm{p}<0.001$ ).

Cooperation between Akt and MAPK signaling is necessary for the PI3K-mediated colony/foci formation by the prostate cancer cells. An important feature of transformed cells is its ability for anchorage-independent growth and protection from anoikis, which is cell death due to the absence of anchoring extracellular matrix proteins to interact with the cell surface integrins (34). Hyper-activation of Akt is known to confer the cells protection from anoikis (35). Anchorageindependent growth allows transformed cells to come out of 
A

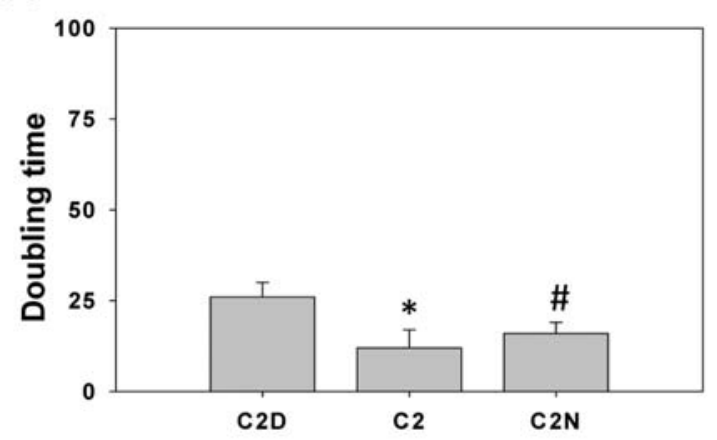

C

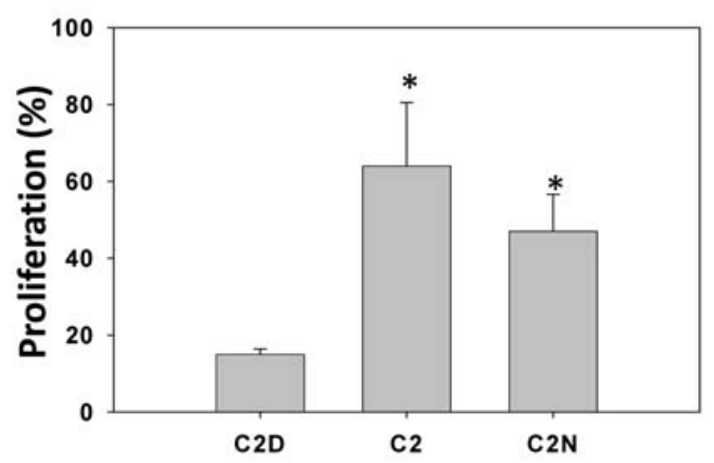

B
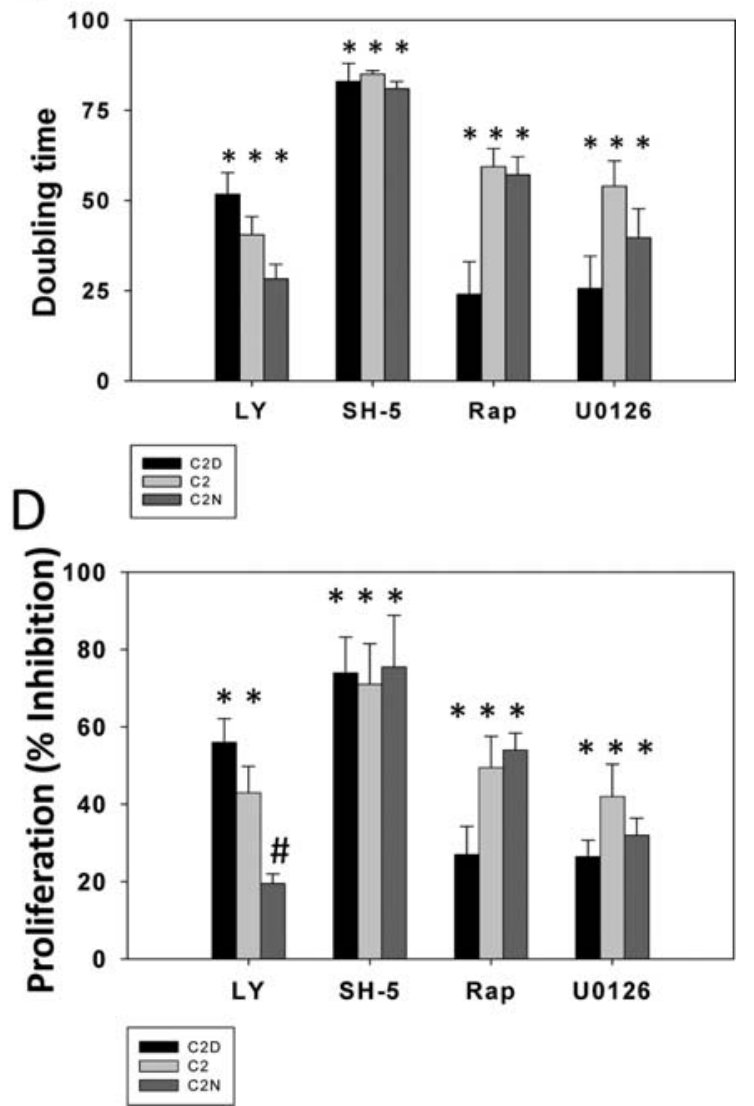

Figure 6. Inhibitors of PI3K, Akt, mTOR and MAPK significantly inhibit prostate cancer cell proliferation. Actively growing TRAMP cell lines (TR-C1D, TR-C2 and TR-C2N) were plated in either 48-well plate (for doubling time) or 6 -well plates at a density of $1 \times 10^{4}$ cells/well in triplicates. After $24 \mathrm{~h}$ incubation in a $\mathrm{CO}_{2}$ incubator at $37^{\circ} \mathrm{C}$, cells were treated with $0.05 \%$ DMSO (vehicle) or EGF (panels A and C) as well as EGF plus the indicated concentrations of PI3K, Akt, mTOR and MAPK inhibitors (LY294002, SH-5, Rapamycin and U0126, respectively) for another 16 h (panels B and D). Cell doubling time was determined according to direct cell count considering the logarithmic growth of cancer cells (www.doubling-time.com). Cell proliferation was determined by the direct counting (panels $\mathrm{A}$ and $\mathrm{B}$ ) at 0 - and 24-h periods or subjected for BrDU exclusion assay (Roche) (panels C and D). The data are presented as mean $\pm \mathrm{SD}(\mathrm{n}=3) ;{ }^{*} \mathrm{p}<0.001,{ }^{*} \mathrm{p}<0.05$.

the contact inhibition and form colonies or foci when they are allowed to grow to confluence on cell culture plates or when allowed to grow in gel-like environment (36). Since Akt and MAPK signaling has certain common, but many non-redundant functions, we sought to determine the effects of targeting PI3K, Akt, mTOR and MAPK individually and in combinations on colony formation. Our experiments using different TRAMP cell lines did not yield any colonies (data not shown) and is in agreement with many other studies where it was observed that TRAMP cells do not form colonies (28). Hence we utilized human prostate cancer C4-2 and PC3 cell lines for these studies. Our study showed that adenovirusmediated expression of myrAkt (myristoilated Akt; constitutively active) resulted in enhanced colony formation in PC3 cells $(\mathrm{p}<0.05)$ (Fig. 7A). In contrast treatment with PI3K inhibitor (LY294002) significantly inhibited colony formation by C4-2 cells, compared to DMSO-treated controls $(\mathrm{p}<0.05)$ (Fig. 7B). Interestingly, inhibition of Akt (SH-5), MAPK (U0126) or mTOR (Rapamycin) did not show any significant effects on colony formation (Fig. 7B). However, combined inhibitions of Akt and MAPK (SH-5 and U0126), as well as mTOR and MAPK (Rapamycin and U0126) significantly inhibited colony formation by PC3 cells $(\mathrm{p}<0.001$ and $\mathrm{p}<0.05$, respectively) (Fig. 7C). Combined inhibition of Akt and mTOR (SH-5 and Rapamycin) did not show either any significant inhibition of colony formation by the PC3 cells (Fig. 7C), probably because both Akt and mTOR share the same signaling pathway in mediating their effects. These results indicate that Akt and MAPK signaling cooperates in PI3Kmediated colony formation by prostate cancer cells.

\section{Discussion}

Inactivating mutations in PTEN is one of the most common reason for prostate cancer incidence in humans (9). This results in the loss of its lipid phosphatase activity and deregulation of PI3K, Akt and MAPK pathways in prostate cancer cells without the involvement of growth factor-RTK activation (10). Cell survival and proliferation, as it pertains to PI3K-Akt signaling pathway, begins with growth factor receptor tyrosine kinases, cytokine receptors and integrins, which upon activation recruit PI3K and Akt to the vicinity of plasma membrane (34). The three gene Akt family (Akt1, Akt2 and Akt3), also known as protein kinase B (PKB), functions as a serine-threonine kinase regulating an array of substrates and mediating cellular processes such as cell 

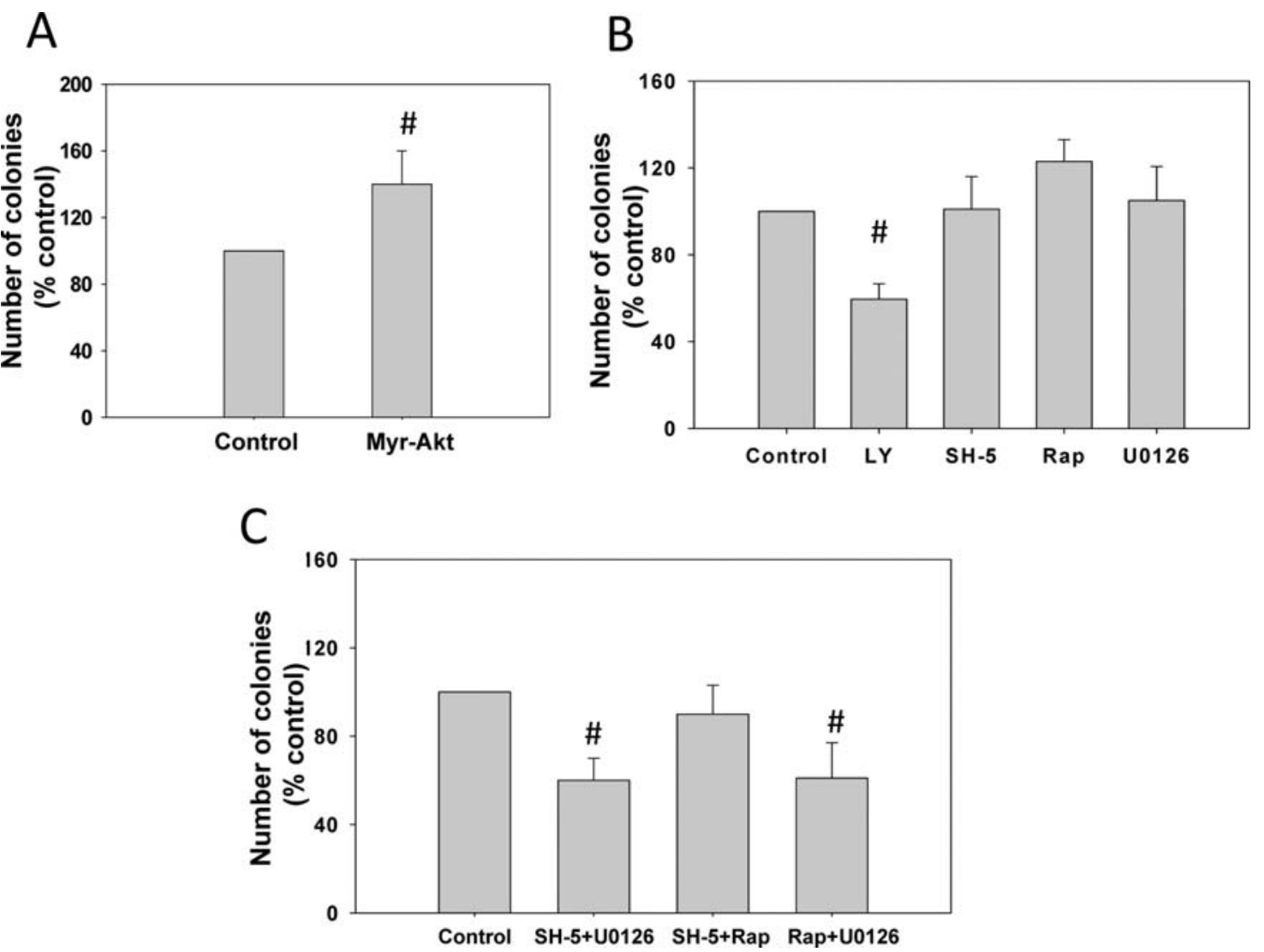

Figure 7. Akt cooperates with MAPK signaling in regulating PI3K-mediated colony formation assay. LNCaP C4-2 or PC3 cells were cultured on 6-well plates until monolayer was reached. Upon reaching monolayer, inhibitors were added as follows: $10 \mu \mathrm{M}$ of LY294002, $10 \mu \mathrm{M}$ of SH-5, $25 \mathrm{nM}$ of Rapamycin and $10 \mu \mathrm{M}$ of U0126, respectively, or in following combinations (10 $\mu \mathrm{M}$ of SH-5 $+25 \mathrm{nM}$ of Rapamycin; $10 \mu \mathrm{M}$ of SH-5 + $10 \mu \mathrm{M} \mathrm{U} 0126$; or $10 \mu \mathrm{M} \mathrm{U} 0126+25 \mathrm{nM}$ of Rapamycin) in serum containing medium. For Myr-Akt studies, PC3 cells were infected with adenovirus particles ( $10^{9}$ pfu) encoding either GFP (control) or Myr-Akt and left for 5 days. Medium and/or inhibitors were changed on a daily basis for 5 days and the number of foci was counted on day 5 . The data are presented as mean $\pm \mathrm{SD}(\mathrm{n}=3) ;{ }^{\#} \mathrm{P}<0.05$.

migration, proliferation, survival, cell cycle, cell size, glucose homeostasis, nutrient response and DNA damage $(34,37)$. Computational analysis has suggested up to 2000 substrates for Akt in mammalian cells (38), out of which only a few have been identified so far. At the same time, cell survival by $\mathrm{PI} 3 \mathrm{~K}$ is also partially regulated by MAPK (39). While considerable efforts have been devoted to targeting PI3K, Akt, mTOR and MAPK directly, no drugs have been approved for clinical use based on these signaling molecules, thus illustrating the difficulty in developing agents that target multi-task kinases, which are also vital for many functions of nonmalignant cells. In the current report, we present evidence that PI3K-mediated effects on prostate cancer cell functions involve cooperation between Akt-mTOR and MAPK signaling. Our finding challenges the existing paradigm that Akt, mTOR or MAPK alone can be suitable targets for prostate cancer therapeutic interventions and emphasizes the need for a cotargeting strategy for Akt (or mTOR) and MAPK for prostate cancer therapy.

Specific inhibitors of PI3K (LY294002), Akt (SH-5; Tricirbine), mTOR (Rapamycin) and MAPK (U0126) are either in use or are proposed for use in clinical trials for treatment of many different cancers. De-regulation of activities of these signaling molecules is often correlated with the Gleason score of prostate cancer patients (23-25). Akin to this, our study on TRAMP cell lines with multiple potencies such as non-tumorigenic, tumorigenic and highly metastatic cells (28) demonstrated a strong correlation between the tumorigenic as well as metastatic ability of prostate cancer cells with the activity status of these signaling molecules. Phosphorylations of Akt, substrates of mTOR (p70 S6 kinase, 4E-BP1 and S6 ribosomal protein), cRaf as well as ERK were all higher in tumorigenic and metastatic cell lines compared to non-tumorigenic cells, suggesting a functional correlation between these signaling molecules and prostate cancer progression. The ability of PI3K inhibitor to blunt EGF-mediated phosphorylations of Akt, mTOR substrates, cRaf and ERK in TRAMP cell lines indicate that a synergism between Akt-mTOR and MAPK may be necessary for PI3Kmediated prostate cancer progression. This is in agreement with a previous report where enhanced Akt and MAPK activities were observed in a pre-clinical model of prostate cancer (40). Interestingly, inhibition of Akt or mTOR also resulted in partial inhibition of EGF-stimulated phosphorylations of cRaf as well as ERK, and vice versa, indicating that there are functional redundancy and cooperation between Akt and MAPK signaling downstream of PI3K activation.

PI3K-Akt signaling pathway has been shown to regulate cell migration in normal $(27,31,34,41)$ and many cancer cells (42), including prostate cancer cells (43). The ability of 
A

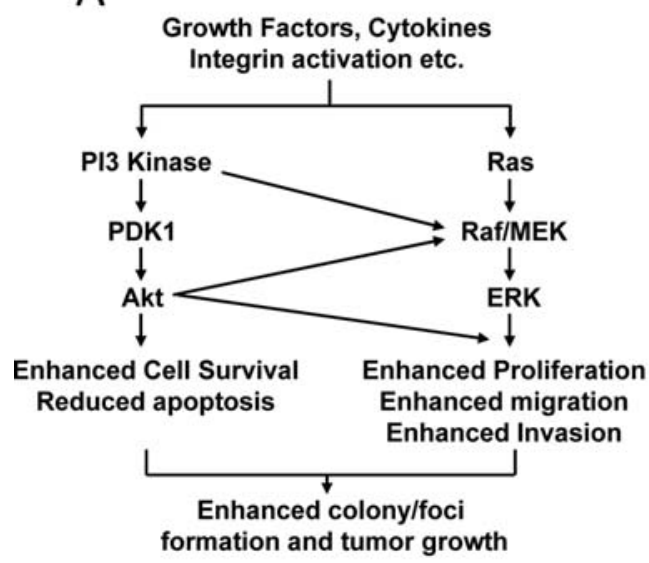

B

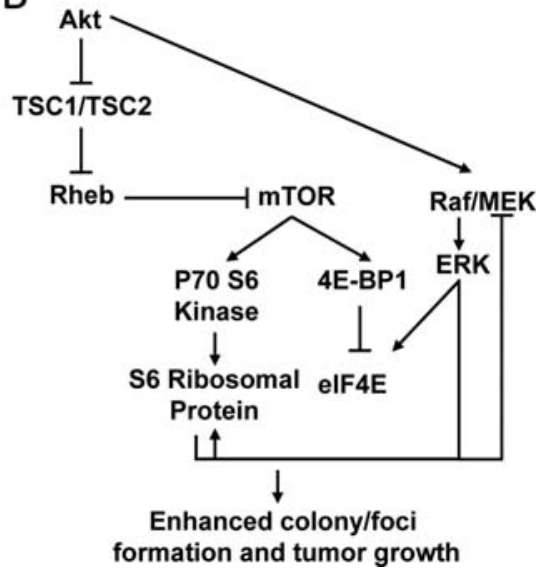

Figure 8. Schematic representation of the working hypothesis. Akt-mTOR and MAPK pathways cooperate in executing PI3K-mediated effects on prostate cancer cells. (A) Growth factor receptor and integrin activation results in activation of PI3K-Akt-mTOR and Ras-Raf-MAPK signaling pathways. While Akt has specific effects on cell survival, inhibition of apoptosis and cell migration, Akt-mTOR and MAPK synergistically regulated proliferation as well as invasion and synergistically regulate prostate cancer cell colony formation and tumor growth. (B) MAPK pathway interacts with mTOR signaling via phosphorylation of eIF4E and p70S6K, two well-known downstream regulators of mTOR. It is likely that MAPK is under the feedback inhibition loop initiated by $\mathrm{p} 70 \mathrm{~S} 6 \mathrm{~K}$

tumorigenic and metastatic TRAMP cell lines to migrate faster than the non-tumorigenic cells suggests that enhanced Akt and MAPK activities in these cell types compared to non-tumorigenic cells may be responsible for the enhanced directional migration. Although PI3K inhibition resulted in impaired migration of TRAMP cells in response to EGF, these effects were even higher upon Akt inhibition, but more or less the same upon MAPK and mTOR inhibitions. This indicate that Akt is a more specific and predominant regulator of cell migration in prostate cancer cells downstream of PI3K, whereas MAPK cooperate with Akt and/or mTOR in modulating prostate cancer cell migration or utilizes a different mechanism to regulate prostate cancer cell migration as has been recently reported (43). Similarly, tumorigenic and metastatic TRAMP cells exhibited enhanced invasive potential compared to non-tumorigenic cells. Effects of EGF on invasion of tumorigenic TRAMP cells were blunted by treatment with PI3K, Akt, mTOR and MAPK inhibitors. Interestingly, mTOR inhibition did not show a significant effect on EGFsimulated invasion of metastatic TRAMP cells, suggesting a more specific role for MAPK in invasion and metastasis compared to mTOR-mediated downstream signaling. Overall, our study show that Akt and MAPK are involved at the different stages of prostate cancer cell migration and invasion and to some extent, their effects are redundant.

The role of Akt and MAPK in the regulation of cell survival and apoptosis is like the chicken-or-egg conundrum. As the name (survival kinase) implies, Akt is well known for its role in the regulation of cell survival and prevention of apoptosis in normal (34) as well as cancer cells (42). At the same time MAPK is also known to enhance cell survival in cancer cells upon PI3K activation (44). However, in this cooperation, which one comes first is still a long-standing question. Many different pathways have been implicated in the Akt-regulated cell survival and inhibition of apoptosis, including BCL-2, BAD, caspases and p53-mediated pathways (45). We observed a trend towards increased cell death (not apoptosis) in tumorigenic and metastatic cells compared to non-tumorigenic TRAMP cells. These differences became more evident upon treatment with PI3K and Akt inhibitors, where significantly enhanced cell death and apoptosis was observed in tumorigenic and metastatic cell lines compared to non-tumorigenic clones. It is likely that the modest increase in cell death among tumorigenic and metastatic cell lines, despite a higher Akt and MAPK activity is due to enhanced proliferation of these cells, as a result of which, cells do not get enough time to prepare for the next cycle of cell division. Our study, however, revealed that inhibitors of mTOR and MAPK do not have any significant effects on cell survival or apoptosis, which may be a specific phenomenon for prostate cancer cells. Together our study shows that in prostate cancer cells, regulation of cell survival and prevention of apoptosis downstream of PI3K activation is mainly controlled by one or more of the Akt-mediated survival pathways.

Both Akt and MAPK have been implicated in the regulation of cell proliferation (32). However, it is still not clear if these effects are functionally redundant or the effects on Akt and MAPK on cell proliferation follow different pathways. While tumorigenic and metastatic TRAMP cells proliferated much faster than the non-tumorigenic cells, Akt-mediated inhibition of TRAMP cell proliferation was most effective compared to PI3K, mTOR and MAPK inhibitions. Similarly, doubling time for TRAMP cells was also the highest in prostate cancer cells treated with Akt inhibitors, compared to PI3K, mTOR and MAPK inhibitors, thus confirming the proliferation data. Together, these studies indicate that Akt is the major regulator of cell proliferation in prostate cancer cells.

Tumor colony/foci forming inhibitor-sensitive assay has been used for many years to study the tumorigenic potential malignant cells as well as to determine the effect of chemotherapeutic agents or inhibitors on tumor growth $(29,30)$. In our study, expression with active form of Akt (myrAkt) in 
PC3 cells resulted in enhanced colony formation thus indicating that elevated Akt activity is responsible for enhanced colony/ foci formation. Interestingly, while PI3 kinase inhibition significantly reduced the number of colonies developed by C4-2 cells, inhibition of Akt, mTOR or MAPK did not show any significant effect on colony formation by human C4-2 or PC3 cells, suggesting that cellular signaling is not always bidirectional in mediating a specific function. This indicates that, even though Akt and MAPK are necessary for the regulation of growth factor-stimulated cell migration, invasion, proliferation and survival, inhibition of Akt, mTOR or MAPK is not enough for prostate cancer therapy. Since PI3K inhibition was enough for significant reduction in number of colonies developed by $\mathrm{C} 4-2$ cells, this suggested that in order to execute PI3K-mediated effects, Akt and MAPK has to cooperate and reconcile their effects at some point.

Cotargeting signaling molecules for cancer therapy, particularly Akt-mTOR and MAPK, has also recently been proposed by many research groups (46). Recent studies have reported the use of cotargeting strategies involving mTOR and MAPK for cancer therapy, including prostate cancer $(47,48)$. This is also in agreement with our previous findings in a Rat1 fibroblast model of oncogenic transformation (27). Multiple models have been proposed for the cooperation between Akt-mTOR and MAPK signaling pathways in the regulation of tumor growth (Fig. 8A and B). In our previous study, we had reported that Akt and MAPK cooperate at the molecular and functional levels in mediating oncogenic transformation of Rat1 fibroblasts (27). These effects were coupled by p21-activated kinase (PAK) and inhibition of p21-activated kinase activity was enough to uncouple these two signaling pathways and inhibit oncogenic transformation and colony formation (49). Both Akt and MAPK have been shown to interact with each other in the regulation of apoptotic molecules Bim and $\operatorname{Bad}(50,51)$. MAPK is also reported to phosphorylate p70 S6 kinase and eIF4E, two downstream effectors of mTOR and cooperate in their activation (38). At the same time, inhibition of p70 S6 kinase (a downstream target of mTORC1) by Rapamycin treat-ment can activate PI3 kinase and Ras signaling via inhibition of a feedback loop regulated by p70 S6 kinase, thus resulting in the activation of PI3 kinase-Akt and MAPK pathways, thus leading to functional redundancy even when mTOR is pharmacologically inhibited (46). Pharmacologic inhibition of mTOR has also been shown to have a rebound effect on Akt activity in mammalian cells (52). Even though not significant, our data supports this report and exhibit a trend in increased colony formation by C4-2 cells upon Rapamycin treatment. In summary, our findings in this study along with previous studies by us $(27,49)$ and other labs $(47,48,53,54)$ highlight the importance of considering a cotargeting strategy involving inhibitions of Akt-mTOR and MAPK pathways for therapeutic interventions for prostate cancer.

\section{Acknowledgements}

This study is funded by the University of Georgia Research Foundation funds provided to Payaningal R. Somanath.

\section{References}

1. Hughes C, Murphy A, Martin C, Sheils O and O'Leary J: Molecular pathology of prostate cancer. J Clin Pathol 58: 673-684, 2005.

2. Mahajna J, Dotan N, Zaidman BZ, Petrova RD and Wasser SP: Pharmacological values of medicinal mushrooms for prostate cancer therapy: the case of Ganoderma lucidum. Nutr Cancer 61: 16-26, 2009.

3. Desgrosellier JS and Cheresh DA: Integrins in cancer: biological implications and therapeutic opportunities. Nat Rev Cancer 10: 9-22, 2010.

4. Jubb AM, Oates AJ, Holden S and Koeppen H: Predicting benefit from anti-angiogenic agents in malignancy. Nat Rev Cancer 6: 626-635, 2006.

5. Parada LF, Tabin CJ, Shih C and Weinberg RA: Human EJ bladder carcinoma oncogene is homologue of Harvey sarcoma virus ras gene. Nature 297: 474-478, 1982.

6. Simon MA, Kornberg TB and Bishop JM: Three loci related to the src oncogene and tyrosine-specific protein kinase activity in Drosophila. Nature 302: 837-839, 1983.

7. Heidecker G, Huleihel M, Cleveland JL, et al: Mutational activation of c-raf- 1 and definition of the minimal transforming sequence. Mol Cell Biol 10: 2503-2512, 1990.

8. Sandgren EP, Quaife CJ, Pinkert CA, Palmiter RD and Brinster RL: Oncogene-induced liver neoplasia in transgenic mice. Oncogene 4: 715-724, 1989.

9. Li J, Yen C, Liaw D, et al: PTEN, a putative protein tyrosine phosphatase gene mutated in human brain, breast, and prostate cancer. Science 275: 1943-1947, 1997.

10. Blanco-Aparicio C, Renner O, Leal JF and Carnero A: PTEN, more than the AKT pathway. Carcinogenesis 28: 1379-1386, 2007.

11. Sircar K, Yoshimoto M, Monzon FA, et al: PTEN genomic deletion is associated with p-Akt and AR signalling in poorer outcome, hormone refractory prostate cancer. J Pathol 218: 505-513, 2009.

12. El-Naggar S, Liu Y and Dean DC: Mutation of the Rb1 pathway leads to overexpression of mTor, constitutive phosphorylation of Akt on serine 473, resistance to anoikis, and a block in c-Raf activation. Mol Cell Biol 29: 5710-5717, 2009.

13. Denley A, Gymnopoulos M, Kang S, Mitchell C and Vogt PK: Requirement of phosphatidylinositol $(3,4,5)$ trisphosphate in phosphatidylinositol 3-kinase-induced oncogenic transformation. Mol Cancer Res 7: 1132-1138, 2009.

14. Sulis ML and Parsons R: PTEN: from pathology to biology. Trends Cell Biol 13: 478-483, 2003.

15. Yoshizaki H, Mochizuki N, Gotoh Y and Matsuda M: AktPDK1 complex mediates epidermal growth factor-induced membrane protrusion through Ral activation. Mol Biol Cell 18: 119-128, 2007.

16. McDonald PC, Oloumi A, Mills J, et al: Rictor and integrinlinked kinase interact and regulate Akt phosphorylation and cancer cell survival. Cancer Res 68: 1618-1624, 2008.

17. Sarbassov DD, Guertin DA, Ali SM and Sabatini DM: Phosphorylation and regulation of Akt/PKB by the rictor-mTOR complex. Science 307: 1098-1101, 2005.

18. Toker A and Newton AC: Akt/protein kinase B is regulated by autophosphorylation at the hypothetical PDK-2 site. J Biol Chem 275: 8271-8274, 2000.

19. Davies MA, Koul D, Dhesi H, et al: Regulation of Akt/ PKB activity, cellular growth, and apoptosis in prostate carcinoma cells by MMAC/PTEN. Cancer Res 59: 2551-2556, 1999.

20. Murillo H, Huang H, Schmidt LJ, Smith DI and Tindall DJ: Role of PI3K signaling in survival and progression of $\mathrm{LNCaP}$ prostate cancer cells to the androgen refractory state. Endocrinology 142: 4795-4805, 2001.

21. Majumder PK and Sellers WR: Akt-regulated pathways in prostate cancer. Oncogene 24: 7465-7474, 2005.

22. Amorino GP and Parsons SJ: Neuroendocrine cells in prostate cancer. Crit Rev Eukaryot Gene Expr 14: 287-300, 2004.

23. Liao Z, Wang S, Boileau TW, Erdman JW Jr and Clinton SK: Increased phospho-AKT is associated with loss of the androgen receptor during the progression of N-methyl-N-nitrosoureainduced prostate carcinogenesis in rats. Prostate 64: 186-199, 2005.

24. McCall P, Witton CJ, Grimsley S, Nielsen KV and Edwards J: Is PTEN loss associated with clinical outcome measures in human prostate cancer? Br J Cancer 99: 1296-1301, 2008. 
25. Bertram J, Peacock JW, Tan C, et al: Inhibition of the phosphatidylinositol 3'-kinase pathway promotes autocrine Fasinduced death of phosphatase and tensin homologue-deficient prostate cancer cells. Cancer Res 66: 4781-4788, 2006.

26. Sebolt-Leopold JS and Herrera R: Targeting the mitogenactivated protein kinase cascade to treat cancer. Nat Rev Cancer 4: 937-947, 2004.

27. Somanath PR, Vijai J, Kichina JV, Byzova T and Kandel ES: The role of PAK-1 in activation of MAP kinase cascade and oncogenic transformation by Akt. Oncogene 28: 2365-2369, 2009.

28. Foster BA, Gingrich JR, Kwon ED, Madias C and Greenberg NM: Characterization of prostatic epithelial cell lines derived from transgenic adenocarcinoma of the mouse prostate (TRAMP) model. Cancer Res 57: 3325-3330, 1997.

29. Bradley EC, Catino JJ, Issell BF, et al: Cell-mediated inhibition of tumor colony formation in agarose by resting and interleukin 2-stimulated human lymphocytes. Cancer Res 45: 1464-1468, 1985.

30. Bradley EC, Ruscetti FW, Steinberg H, Paradise C and Blaine K: Inhibition of differentiation and proliferation of colonystimulating factor-induced clonal growth of normal human marrow cells in vitro by retinoic acid. J Natl Cancer Inst 71: 1189-1192, 1983.

31. Somanath PR, Kandel ES, Hay N and Byzova TV: Akt1 signaling regulates integrin activation, matrix recognition, and fibronectin assembly. J Biol Chem 282: 22964-22976, 2007.

32. Dillon RL and Muller WJ: Distinct biological roles for the Akt family in mammary tumor progression. Cancer Res 70: 4260-4264, 2010.

33. Galabova-Kovacs G, Kolbus A, Matzen D et al: ERK and beyond: insights from B-Raf and Raf-1 conditional knockouts. Cell Cycle 5: 1514-1518, 2006.

34. Somanath PR, Razorenova OV, Chen J and Byzova TV: Akt1 in endothelial cell and angiogenesis. Cell Cycle 5: 512-518, 2006.

35. Shiojima I and Walsh K: Role of Akt signaling in vascular homeostasis and angiogenesis. Circ Res 90: 1243-1250, 2002.

36. Shin SI, Freedman VH, Risser R and Pollack R: Tumorigenicity of virus-transformed cells in nude mice is correlated specifically with anchorage independent growth in vitro. Proc Natl Acad Sci USA 72: 4435-4439, 1975.

37. Vivanco I and Sawyers CL: The phosphatidylinositol 3-kinase AKT pathway in human cancer. Nat Rev Cancer 2: 489-501, 2002.

38. Hay N: The Akt-mTOR tango and its relevance to cancer. Cancer Cell 8: 179-183, 2005.

39. Lu Z, Cox-Hipkin MA, Windsor WT and Boyapati A: 3-phosphoinositide-dependent protein kinase-1 regulates proliferation and survival of cancer cells with an activated mitogen-activated protein kinase pathway. Mol Cancer Res 8: 421-432, 2010
40. Gao H, Ouyang X, Banach-Petrosky WA, Gerald WL, Shen MM and Abate-Shen C: Combinatorial activities of Akt and B-Raf/ Erk signaling in a mouse model of androgen-independent prostate cancer. Proc Natl Acad Sci USA 103: 14477-14482, 2006.

41. Chen J, Somanath PR, Razorenova O, et al: Akt1 regulates pathological angiogenesis, vascular maturation and permeability in vivo. Nat Med 11: 1188-1196, 2005.

42. Carnero A: The PKB/AKT pathway in cancer. Curr Pharm Des 16: 34-44, 2010.

43. Gan Y, Shi C, Inge L, Hibner M, Balducci J and Huang Y: Differential roles of ERK and Akt pathways in regulation of EGFR-mediated signaling and motility in prostate cancer cells. Oncogene (In press).

44. Sun CY, Hu Y, Huang J, et al: Brain-derived neurotrophic factor induces proliferation, migration, and VEGF secretion in human multiple myeloma cells via activation of MEK-ERK and PI3K/AKT signaling. Tumour Biol 31: 121-128, 2010.

45. Wang G, Reed E and Li QQ: Apoptosis in prostate cancer: progressive and therapeutic implications (Review). Int J Mol Med 14: 23-34, 2004.

46. Grant S: Cotargeting survival signaling pathways in cancer. J Clin Invest 118: 3003-3006, 2008

47. Kinkade CW, Castillo-Martin M, Puzio-Kuter A, et al: Targeting AKT/mTOR and ERK MAPK signaling inhibits hormone-refractory prostate cancer in a preclinical mouse model. J Clin Invest 118: 3051-3064, 2008.

48. Kharas MG, Janes MR, Scarfone VM, et al: Ablation of PI3K blocks BCR-ABL leukemogenesis in mice, and a dual PI3K/ mTOR inhibitor prevents expansion of human BCR-ABL ${ }^{+}$ leukemia cells. J Clin Invest 118: 3038-3050, 2008.

49. Kichina JV, Goc A, Al-Husein B, Somanath PR and Kandel ES: PAK1 as a therapeutic target. Expert Opin Ther Targets 14: 703-725, 2010

50. Maddika S, Ande SR, Panigrahi S, et al: Cell survival, cell death and cell cycle pathways are interconnected: implications for cancer therapy. Drug Resist Updat 10: 13-29, 2007.

51. Panka DJ, Atkins MB and Mier JW: Targeting the mitogenactivated protein kinase pathway in the treatment of malignant melanoma. Clin Cancer Res 12: S2371-S2375, 2006.

52. Guertin DA and Sabatini DM: The pharmacology of mTOR inhibition. Sci Signal 2: pe24, 2009.

53. Stommel JM, Kimmelman AC, Ying H, et al: Coactivation of receptor tyrosine kinases affects the response of tumor cells to targeted therapies. Science 318: 287-290, 2007.

54. Shah NP, Skaggs BJ, Branford S, et al: Sequential ABL kinase inhibitor therapy selects for compound drug-resistant BCR-ABL mutations with altered oncogenic potency. J Clin Invest 117: 2562-2569, 2007. 